\title{
Social Intelligence of Undergraduate Students In Relation To Their Gender and Subject Stream
}

\author{
* Dr. Sumanlata Saxena, ** Dr. Rajat Kumar Jain \\ *Assistant Professor, Education Department Kalyan Post Graduate College, Sector-7, Bhilai Nagar, \\ Chhattisgarh \\ **Assistant Professor, Education Department Shri Shankaracharya Mahavidyalya, Sector-6, Bhilai Nagar, \\ Chhattisgarh
}

\begin{abstract}
Social Intelligence is of more importance in the present life style due to growing tensions stresses and various complexities. It can be learned, developed and used as an effective life skill for managing personal life, interpersonal relationships and achieving success in all the walks of life.

The present study was conducted to know the social intelligence of male and female undergraduate students of science and Arts subject streams studying in various degree colleges of Bhilai city, Chhattisgarh. For this purpose descriptive survey method was used. 60 male and 60 female undergraduate students were selected, for the sample by adopting stratified disproportionate random sampling technique. The data was collected by using Social Intelligence Scale (SIS) constructed and standardized by Chadda and Ganesan (2009). The data was analyzed by using ' $t$ ' test.

The findings of gender analysis indicates that female student's posses more social intelligence than male students and analysis of stream indicates that arts students are having greater social intelligence than students of other streams.
\end{abstract}

Key Words: Social Intelligence, Undergraduate Students, gender and subject streams.

\section{Introduction}

Thorndike (1920) studies Intelligence in its three facets, pertaining to understand \& manage ideas (abstract intelligence), concrete objects (mechanical intelligence) and people (social intelligence). Social intelligence is the person's ability to understand and manage other people and to engage in adaptive social interactions (Thorndike, 1920). Social intelligence has two key constituents which are distinctly personal and social in nature, one is intrapersonal intelligence and other is interpersonal intelligence. Intrapersonal intelligence is the person's ability to gain access to his or her own internal, emotional life while interpersonal intelligence is the individual's ability to notice and make distinctions among other individuals.

Several definitions of social intelligence have been offered by theorists, but all share two common components (a) the awareness of others (b) their response and adaptation to other and the social situations (Goleman, 2006; Kobe, Rester-palmon and Rickcrs, 2001). Social intelligence is a mental ability distinct from abstract and mechanical intelligence (Thorndike, 1920). Ford and Tisak(1983) defined social intelligence in terms of behavioral outcomes and were successful in supporting a distinct domain of social intelligence. They defined it as "one's ability to accomplish relevant objectives in specific social settings". Marlowe(1986) equated social intelligence to social competence. He defined it as the ability to understand the feelings, thoughts and behaviors of persons, including one self, interpersonal situations and to act appropriately upon that understanding." (1982, P-15)

It is difficult to lead a successful life in a society without social intelligence. Social intelligence helps an individual to develop healthy co-existence with other people. Socially intelligent people behave tactfully and prosper in life. Social intelligence is useful in solving the problems of social life and help in tackling various social tasks. Thus social intelligence is an important developmental aspect of education. Several studies have shown that social intelligence is multidimensional and distinguishable from general intelligence domains (Jones and Day, 1997; Marlowe, 1986; Weis et al.). These concepts of social intelligence are incorporating internal \& external perceptions, social skills and other psychosocial variables, (Taylor,1990). Marlowe's (1986) model of social intelligence comprised five domains- personal attitude, social performance skills, empathetic ability, emotional expressiveness and confidence. Pro-social attitude is indicated by having an interest and concern for others, social performance skills is demonstrated in appropriate interaction with other, empathetic ability refers to one's ability to identify with others, emotion expressiveness describes ones emotionality towards others and confidence in social situations is based on one's comfort level in social situations Weis and Sub(2007) showed that social undertaking and social knowledge were separate constructs of social intelligence. Willimann, fedlt and Amelang (1997) viewed supporting harmony and restoring equilibrium between individuals as acts of being socially intelligent. 
The review of related literature on social intelligence reveals that the construct of social intelligence has attracted many researchers. Success in academic performance of the students depends on their intelligence (Panigrahi, 2005) and it is positively related to social intelligence (Brown \& Anthony, 1990). Bailey (1968) studied the assessment of social intelligence among the students of fifth grade using friendship rating which revealed that social intelligence (pear acceptance) co-varies with academic achievement. Higher achievers score more on social intelligence (Saxena \& Panigrahi, 2009). Riggio, Messamer and Throkomorton (1991) revealed that academic and social intelligence are conceptually distinct but overlapping constructs.

Singh (2007) found no significant difference in social intelligence between low creative \& high creative adolescents and between high creative boys and high creative girls. Kaur and Kalaramna (2004) conducted the study to assess the existing levels of inter-relationship between home environments, social intelligence and socio-economic status and found that socio-economic status and home environment affect social intelligence. Vyrost and Kyselova (2006) investigated interconnections between social intelligence, wisdom, values and interpersonal personality traits. The result revealed close mutual relations between social intelligence and wisdom related knowledge. Chesnokova (2005) observed that the development of social intelligence with age goes through stages. Gnanadevan (2007) concluded that the social intelligence scores of the students differed significantly with respect to caste, mother's education and parent's income but did not differ significantly with respect to gender, father's education, mother's occupation or father's occupation. Gakhar and Bains (2009) found that arts students are more socially intelligent than science students.

Various studies have been conducted on social intelligence in relation to academic achievements (Bailey, 1968; Brown \& Anthony, 1990; Riggio, Messamer \& Throkomorton, 1991 and Saxena \& Panigrahi, 2009). Effect of some other variables on social intelligence has also been studied such as creativity (Singh, 2007), home environment and socio-economic status (Kaur \& Kalaramna, 2004), wisdom, values and interpersonal personality traits (Vyrost \& Kyselova, 2006), age (Chesnokova, 2005), caste, gender, parents and parent's occupation(Gnanadevan,2007). However, it was felt that it is necessary to study the effect of gender and subject stream on social intelligence.

The review of literature reveals that this relationship has not been explored yet, hence the present investigation was undertaken to find out the social intelligence of undergraduate students in relation to their gender and subject streams.

Objectives of the Study: The objectives of the present study were as follow-

(1) To Study the social intelligence of undergraduate students in relation to their gender.

(2) To Study the social intelligence of undergraduate students in relation to their subject streams.

Hypotheses: The present study is based on the following hypotheses-

(1) There is no significant difference between social intelligence of undergraduate student on the basis of their gender.

(2) There is no significant difference between social intelligence of undergraduate students on the basis of their subject streams.

\section{Research Model-}

\section{Methodology}

\section{Participants-}

Descriptive survey model was used in the present study.

For the selection of sample stratified disproportionate random sampling technique was adopted. The sample consisted of 120 first year college students comprising 60 male and 60 female belonging to research science and arts subject from the degree college of Bhilai city, Chhattisgarh.

\section{Measures-}

Social intelligence scale (SIS) constructed and standardized by chadda and Ganeshan (2009) was used to assess the social intelligence of undergraduate students. The scale has eight dimensions namely: Patience, cooperativeness, confidence level, sensitivity, recognition of social environment, tactfulness, sense of humour and Memory. The respondents were instructed to tick mark one out of the three choices as per applicability of the response to them. The total social intelligence score was determined by summing up the scores of all the dimensions.

Statistics used-

Mean, standard deviation and ' $t$ ' ratio were used to analyze the date.

\section{Result and Discussion}

The table-1 indicates that there exists significant difference between male and female undergraduate students on overall social intelligence. Out of eight dimension significant difference was observed in patience, 
cooperativeness, sensitively and recognition of social environment between male and female students. However, significant difference between male and female students was not observed in confidence level, Tactfulness, sense of humour and memory dimensions. Table indicates that females are more socially intelligent than males. Also, females have more patience and sensitivity, better cooperativeness and recognition of social environment than their counterparts. At the same time confidence level, tactfulness, sense of humor and memory are the dimensions in which males and females do not have any significant difference. This result is in contrast to the observations made by Gnanadevan (2007) who did not found any gender differences.

Table-1 Values of Mean, SD and t-ratio to show the difference in social intelligence of undergraduate student in relation to gender.

\begin{tabular}{|c|c|c|c|c|c|}
\hline S.No. & Variable & Group & $\mathbf{M}$ & SD & T-Ratio \\
\hline \multirow{2}{*}{1.} & \multirow{2}{*}{ Social Intelligence } & Male & 108.35 & 8.12 & \multirow{2}{*}{$2.98 * *$} \\
\hline & & Female & 111.66 & 9.03 & \\
\hline \multirow{2}{*}{2.} & \multirow{2}{*}{ Patience } & Male & 21.13 & 1.81 & \multirow{2}{*}{$3.49 * *$} \\
\hline & & Female & 22.10 & 2.45 & \\
\hline \multirow{2}{*}{3.} & \multirow{2}{*}{ Cooperativeness } & Male & 25.82 & 2.50 & \multirow{2}{*}{$3.50 * *$} \\
\hline & & Female & 27.13 & 3.24 & \\
\hline \multirow{2}{*}{4.} & \multirow{2}{*}{ Confidence Level } & Male & 22.01 & 3.01 & \multirow{2}{*}{0.16} \\
\hline & & Female & 22.07 & 2.76 & \\
\hline \multirow{2}{*}{5.} & \multirow{2}{*}{ Sensitivity } & Male & 20.28 & 2.64 & \multirow{2}{*}{$3.69 * *$} \\
\hline & & Female & 21.63 & 3.05 & \\
\hline \multirow{2}{*}{6.} & \multirow{2}{*}{$\begin{array}{l}\text { Recognition of Social } \\
\text { Environment }\end{array}$} & Male & 0.91 & 0.68 & \multirow{2}{*}{$3.77 * *$} \\
\hline & & Female & 1.25 & 0.73 & \\
\hline \multirow{2}{*}{7.} & \multirow{2}{*}{ Tactfulness } & Male & 4.05 & 1.17 & \multirow{2}{*}{1.25} \\
\hline & & Female & 4.22 & 0.93 & \\
\hline \multirow{2}{*}{8.} & \multirow{2}{*}{ Sense of Humor } & Male & 3.98 & 1.42 & \multirow{2}{*}{1.61} \\
\hline & & Female & 4.20 & 1.21 & \\
\hline \multirow{2}{*}{9.} & \multirow{2}{*}{ Memory } & Male & 10.28 & 1.40 & \multirow{2}{*}{1.81} \\
\hline & & Female & 9.63 & 1.94 & \\
\hline
\end{tabular}

Table-2 Values of means standard deviation and t-ratio to show the difference in social intelligence of undergraduate students in relation to their subject streams.

\begin{tabular}{|c|c|c|c|c|c|}
\hline S.No. & Variable & Group & $\mathbf{M}$ & SD & T-Ratio \\
\hline \multirow{2}{*}{1.} & \multirow{2}{*}{ Social Intelligence } & Science & 107.06 & 7.82 & \multirow{2}{*}{$2.46^{*}$} \\
\hline & & Arts & 109.67 & 8.57 & \\
\hline \multirow{2}{*}{2.} & \multirow{2}{*}{ Patience } & Science & 20.37 & 2.21 & \multirow{2}{*}{$2.29 *$} \\
\hline & & Arts & 20.99 & 1.92 & \\
\hline \multirow{2}{*}{3.} & \multirow{2}{*}{ Cooperativeness } & Science & 25.87 & 2.30 & \multirow{2}{*}{$4.25^{*}$} \\
\hline & & Arts & 27.40 & 3.19 & \\
\hline \multirow{2}{*}{4.} & \multirow{2}{*}{ Confidence Level } & Science & 21.53 & 2.78 & \multirow{2}{*}{1.25} \\
\hline & & Arts & 21.98 & 2.58 & \\
\hline \multirow{2}{*}{5.} & \multirow{2}{*}{ Sensitivity } & Science & 20.47 & 2.60 & \multirow{2}{*}{$4.43 *$} \\
\hline & & Arts & 22.02 & 2.70 & \\
\hline \multirow{2}{*}{6.} & \multirow{2}{*}{$\begin{array}{l}\text { Recognition of Social } \\
\text { Environment }\end{array}$} & Science & 0.93 & 0.57 & \multirow{2}{*}{$4.44 *$} \\
\hline & & Arts & 1.33 & 0.81 & \\
\hline \multirow{2}{*}{7.} & \multirow{2}{*}{ Tactfulness } & Science & 3.40 & 0.80 & \multirow{2}{*}{$2.75^{*}$} \\
\hline & & Arts & 3.73 & 1.06 & \\
\hline \multirow{2}{*}{8.} & \multirow{2}{*}{ Sense of Humour } & Science & 3.86 & 1.31 & \multirow{2}{*}{0.84} \\
\hline & & Arts & 3.73 & 1.06 & \\
\hline \multirow{2}{*}{9.} & \multirow{2}{*}{ Memory } & Science & 9.80 & 1.27 & \multirow{2}{*}{$4.0 *$} \\
\hline & & Arts & 8.80 & 2.48 & \\
\hline
\end{tabular}

It is clear from the table no-02 that science and arts undergraduate students do differ in overall social intelligence. Significant difference is also found in dimension-Patience, cooperativeness, sensitivity, recognition of social environment, Tactfulness and Memory, but not in confidence level and sense of humor. It means that arts undergraduate students are more socially intelligent than science students. Marlowe (1986) suggested that individuals who are socially intelligent appear to experience a rich, meaningful life, as opposed to truncated 
affective experiences. Furthermore, aspects of social intelligence have been found to be associated with enhanced social problem-solving abilities (Jones \& Day, 1991), experienced leadership (Kobeetal, 2001), and positive interpersonal experience (Cheng et al.). At the same time they also possess better patience, cooperativeness, sensitivity, recognition of social environment and tactfulness. However, science undergraduate students seem to possess better memory power than their counterparts. At the same time no significant difference is observed in their confidence level \& sense of humour. Gakhar and Bains (2009) also found arts students to be more socially intelligent than science stream student.

\section{References}

[1] Bailey, J.A(1968) Social intelligence, achievement and the elementary school child. www.eric.ed.gov

[2] Brown and Anthony (1990) Continuing the search for social intelligence.

[3] Personality and individual difference, 2(5) 463-470.

[4] Chadda, N.K. and Ganesan, U.(2009) Manual of social intelligence scale, Agra National Psychological cooperation.

[5] Chesnokova, O. (2005), Cunning and social intelligence in children. www.lancs.ac.uk

[6] Gakhar, S.C. and Bains, (2009) A study of social intelligence and achievement motivation of students of arts and science stream. Journal of educational studies, 7(2) 56-59.

[7] Gnanadevan, R. (2007) Social intelligence of higher secondary students in relation to their socio-economic status, Journal of Community Guidance and Research, 24(3) 340-346.

[8] Kaur, H and Kalaramna, A(2004)Study of interrelationship between home environment, social intelligence and socio-economic status among male \& female, Journal of Human Ecology, 16(2), 137-140.

[9] Panigrahi, M.R. (2005) Academic Achievement in relation to intelligence \& socio-economic status of high school students. Edutracks, 5(2), 26-27.

[10] Riggio, R.E. ; Messamer, J. and Throckmorton, B(1991) Social and academic intelligence: conceptually distinct but overlapping contracts. Personality and Individual Differences, 695-700.

[11] Saxena S. and Panigrahi S.(2009)Social intelligence of high and low achieves undergraduate students. Journal of Educational studies, 7(2), 31-34

[12] Singh, S. (2007)Emotional intelligence, social intelligence, adjustment and personality differentials of adolescents with high \& low creativity Ph.D.Thesis P.U.Chamdigerth

[13] Vyrost, J. and Kyselova, M.(2006) Personality correlates of social intelligence. Studia Psychologica 48(3), $207-212$.

[14] Weis, S. \& Sub, H (2007) Reviving the search for social intelligence. A multi trait, multi method study of its structure and construct validity personality and individual differences. 142, P-2, 3.

[15] Wong, C.T., Day, J.D, Maxwell, S.E. and Meara, M.M (1995) A multi trait multi method study of academic and social intelligence in college students. Journal of educational psychology, 87(1), 117-133.

[16] Willmann, E., Feldt, K., and Amelang, M. (1997) Prototypical behavior pattern of social intelligence. An intercultural comparison between Chinese and German subjects, international Journal of psychology, 32(5), 329-346.

[17] Taylor, E.H. (1990) The assessment of social intelligence, psychotherapy, 27(3), 445-457.

[18] Kobe, L.M., Reiter-palmon, R. and Rickers, J.D (2001) Self reported leadership experiences in relation to inventoried social and emotional personality and social, 20(2), 154-163.

[19] Marlowe, H.A. (1986)Social intelligence: Evidence for multi dimensionality and construct independence, Journal of educational psychology, 78(1), 52-58.

[20] Jones, K. and Day, J.D. (1997) Discrimination of two aspects of cognitive social intelligence from academic intelligence Journal of educational psychology, 89(3), 486-497.

[21] Cheng, C., Chiu, C, Hong, Y., and Cheung, J.S. (2001) Discriminative facility and its role in the perceived qualities of interactional experiences, Journal of personality, 69(5), 765-786.

[22] Gereman, D. (2006) Social intelligence: The new science of humour relationship, Newyork: Bantam Books. 